\title{
Requesting for Custom Denomination in Automatic Teller Machine Withdrawal
}

\author{
K. Navatha ${ }^{1}$, Naga Durga Saile.K ${ }^{2}$, E. Soumya ${ }^{3}$ \\ Assistant Professor, Dept. of CSE, St Martin's Engineering College, Hyderabad, India ${ }^{1,2}$ \\ Assistant Professor, Dept. of IT, St Martin's Engineering College, Hyderabad, India ${ }^{3}$
}

\begin{abstract}
An easy cash drawing system, Automated Teller Machine (ATM) has become an integral part of our society. For withdrawal service, existing ATM machines asks only how much money do you want to withdraw after the user authentication. It does not ask what denominations the customer wants. So implementing custom denomination request in an ATM withdrawal is an added advantage to the customer. It avoids the overhead of a customer by giving custom denomination for small and large amount withdrawals.
\end{abstract}

Keywords: Automated Teller Machine, Cash Withdrawal, Custom Denomination, Customer.

\section{INTRODUCTION}

An ATM (Automatic Teller Machine) also called as ABM (Automated Banking Machine) is an electronic telecommunication device enables the banking customers to do some bank activities. ATM minimizes the overhead of a customer by providing the basic operations actually what the user does regularly [3]. For example, to use the cash withdrawal service by a customer, the customer has to go to bank, filling up an withdrawal form and waits in a big queue to get the chance [1]. To complete this it takes 15-20 minutes minimum. Sometimes it may take hours also. Now a day's no one is ready to spend their valuable time for regular banking operations like Balance Enquiry, cash withdrawal, etc. Everyone is busy with their life style. So everyone is looking for easy accessing of those services. For that, ATM helps a lot to the customers by providing these services [4]. It is a GUI (Graphical User Interface) based and user friendly also.

1. Cash withdrawal

2. Balance Enquiry

3. Mini Statement (of recent 10 transactions)

Later the services in ATM are increased to get the customer satisfaction. That includes

1. Cash Deposit

2. Cheque Deposit

3. Funds Transfer

4. Credit card payment

5. Utility Bill payment

6. Cheque Book request

7. Mobile, DTH etc. recharge \& topups.

8. User details updation

\section{RELATED WORK}

Among the available services, the customers mostly utilize cash withdrawal service of an ATM. For example if a customer want move from one place to place he no need to carry cash along with him/her. There may be theft or misplace (due to absences of mind) if they carry money along with them. At that time ATM plays vital role to get money at any time and at any place.
To avail ATM services the customer should get Debit/credit card from the bank in which a customer has an account. At that time every customer is supplied with a four digit PIN (personal identification number). This is mandatory to do the transaction in an ATM.

Withdrawal in an ATM involves various steps:

1. Insert card

2. Select preferred language

3. Enter 4 digit PIN number

4. If PIN is correct, it shows available services.

5. Select cash withdrawal from available services.

6. Choose type of account from which do you want to withdraw.

7. Enter the amount you need to withdrawal.

If requested amount is available in account then it gives the cash in various denominations.

While withdrawing cash ATM does not ask the user for denomination. Sometimes this may create a problem to the customer.

For example, customer decides to withdraw Rs. 1000 from ATM with the denomination of 5 hundred notes and one five hundred note. But ATM may give single 1000 note or two 500 notes. Where will customer get required change for money? And there is no way of guarantee that whether the notes dispensed by ATM are original or fake?

\section{PROPOSED METHODOLOGY}

To avoid above type of issues for the customers, we proposed a methodology for denomination request for withdrawal module and detection of fake currency in an ATM.

- Custom Denomination Request for withdrawal:

Denomination is a proper description of a currency amount, usually for banknotes or coins. Requesting denomination will helpful to customer for requesting custom denominations based on their use. The following is the sample 'c language' code for requesting denomination in ATM. 
/* Sample C code for requesting denomination in ATM */ bal= acnt_bal;

Printf(“enter withdrawl amount");

Scanf(“\%d",\&withdrawl);

If(withdrawl<=bal \&\& withdrawl $>=0$ )

\{

denom:

Printf("enter denomination for withdrawl");

Printf("enter no.of Rs.100 notes do you want");

Scanf("\%d",\&h);

Printf(“enter no.of Rs.500 notes do you want");

Scanf(“\%d",\&fh);

Printf(“enter no.of Rs.1000 notes do you want");

Scanf(“\%d",\&th);

hndrnt $=\mathrm{h} * 100$;

fivehndrnt $=\mathrm{fh} * 500$;

thsndnt $=$ th $* 1000$;

ttlwtdrl=hndrnt+fivehndrnt+thsndnt; if(withdrawl==ttlwtdrl)

bal=bal-withdrawl;

Request the cash cassettes to dispense the requested denomination amounts.

\}

Else

\{

Printf("The sum of total of all denominations should equal to withdrawl amount"); goto denom;

\}

\}

Else

\{

Printf("No sufficient funds in your account");

\}

\section{FLOWCHART FOR PROPOSED SYSTEM:}

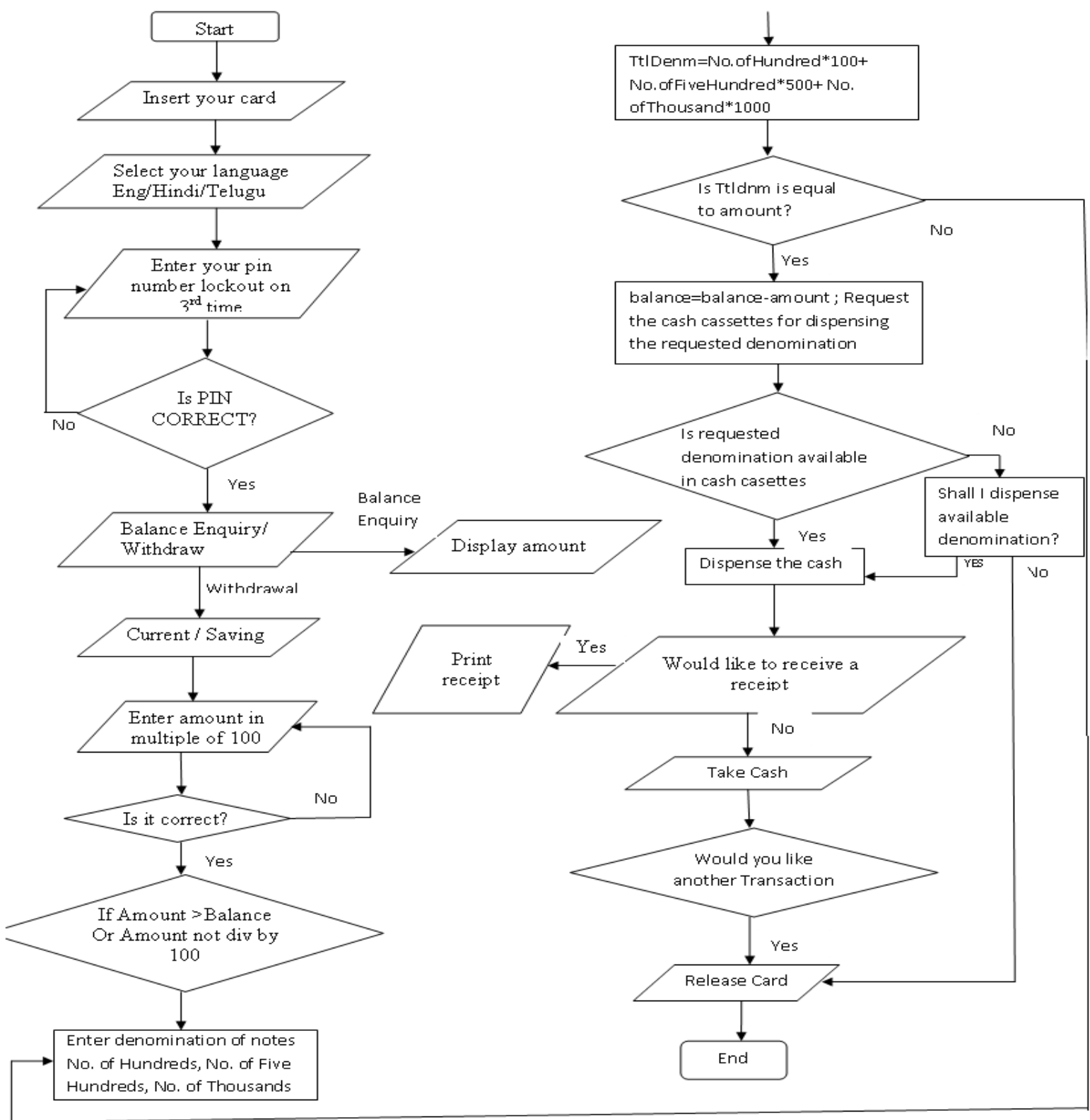




\section{CONCLUSION}

The method proposed in this paper provides flexible and time saving to a customer. And this avoids the overhead of a customer by providing custom denomination request for ATM withdrawal. With this the customer can easily get what denomination he needs and no need to think about how to get and where to get the change.

\section{REFERENCES}

[1] ANANTH VIJAY KALA "India's Small Change Problem" http://blogs.wsj.com/indiarealtime/2013/06/12/indias-small-changeproblem/

[2] Jerry Shaw, Demand media "Benefits \& Drawbacks of using an ATM card "http://classroom.synonym.com/benefits-drawbacksusing-atm-card-13651.html

[3] "Working of Automatic Teller Machine "http://www.circuitstoday. com/working-of-automatic-teller-machine-atm

[4] K. Satish, Y.K.Viswanadham, I Leela Priya "Money to ATM-Fake Currency Detection" International Journal of Computer Science and Information Technologies, Vol. 3, Issue 5, 2012, ISSN: 0975-9646.

[5] A. Kavitha, Dr. R. China Appala Naidu, P. Srinivasulu, K. Meghana "Identify the Fake Currency in Automatic Teller Machine" International Journal of Innovative Research in Computer and Communication Engineering, Vol. 3, Issue 11, November 2015, ISSN: 2320-9801. 